\title{
Assessment of the relationship between demographic variables and knowledge, attitude and practice of Azad Islamic University students about sexually transmitted diseases in 2018
}

\author{
Tahereh Kamalikhah ${ }^{1,2}$, Mehran Akbari $^{3}$, Maede Parhode ${ }^{4}$, Leila Sabzmakan ${ }^{5}$, Razieh Khosrorad ${ }^{6}$, Ali Mehri \\ ${ }^{1}$ Department of Health Education and Health Promotion, Semnan University of Medical Sciences, Semnan, Iran \\ ${ }^{2}$ Department of Health Education and Health Promotion, Science and Research Branch, Islamic Azad University, Tehran, Iran \\ ${ }^{3}$ Department of Nursing, Khomein University of Medical Sciences, Khomein, Iran \\ ${ }^{4}$ Student Research Committee, Semnan University of Medical Sciences, Semnan, Iran \\ ${ }^{5}$ Department of Health Education and Health Promotion, Alborz University of Medical Sciences, Karaj, Iran \\ ${ }^{6}$ Department of Health Education, Educational Neuroscience Research Center, Sabzevar University of Medical Sciences, Sabzevar, Iran \\ ${ }^{7}$ Department of Health Education and Health Promotion, Sabzevar University of Medical Sciences, Sabzevar, Iran
}

\begin{abstract}
Introduction: Sexually transmitted diseases (STDs) are one of the health concerns of the new century and likelihood of morbidity in young people is high. Knowledge and attitude about these diseases and demographic characteristics of people have and important role in reduction of their incidence and prevalence. Therefore, this study aimed to evaluate the relationship between demographic variables and knowledge, attitude and practice of young people regarding STDs

Material and methods: This study is a descriptive cross-sectional study, 500 students including were participated in 2018. Cluster random sampling was applied through the selection of various universities and colleges in 5 Azad units: North, South, East, West and Center of Tehran. Students were studying in art, human science, engineering, base science etc., majoring in B.A. and B.Sc. degrees. The data gathering tool was a researcher-made questionnaire. Its validity was confirmed by content and face validity. Reliability was assessed using the test-re-test method. Data were analyzed using SPSS version 21 software and descriptive and analytical statistical tests such as t test and ANOVA.

Results: There was no significant relationship between students' mean knowledge and gender $(p=0.434)$, but relationships of attitude and practice (risk and preventive) with gender $(p<0.001)$ and knowledge, and attitude $(p<0.001)$ with marital status were observed, female gender being associated with better attitude and practice and married women having better knowledge and attitude. The ANOVA and Kruskal-Wallis test and the least significant difference (LSD) test showed no significant difference between the students of Azad University and their field of study with their knowledge.

Conclusions: Intervention in the study population was needed in order to increase awareness, change attitude and reduce risky behaviors and integrate education of sexually transmitted diseases in the academic curriculum. On the other hand, the establishment of valid websites, weblogs and valid channels in social media by medical universities is recommended because students reported Internet and social media as the most common way of getting information about STDs, with the focus on male students and single students, who need more education and attention. Students reported the Internet
\end{abstract}

Address for correspondence: Ali Mehri, Department of Health Education and Health Promotion, Sabzevar university of Medical Sciences, Sabzevar, Iran, e-mail: hadimehri1386@gmail.com
Article history:

Received: 18.04.2020

Received in revised form: 26.11 .2020

Accepted: 05.03.2021

Available online: 30.08 .2021
International Journal of HIV-Related Problems

HIV \& AIDS

R e v i e w 
as the most frequent way of acquiring knowledge about sexually transmitted diseases (28.8\%) followed by social media $(23.2 \%)$ and the lowest rate of information about sexually transmitted infections was radio followed by health care providers and professors.

HIV AIDS Rev 2021; 20, 3: 201-207

DOI: https://doi.org/10.5114/hivar.2021.109558

Key words: sexually transmitted diseases, sexually transmitted infections, STDs, STIs, knowledge, attitude.

\section{Introduction}

Health promotion and disease prevention is one of the important goals of health systems despite efforts to promote health, sexually transmitted diseases (STDs) are still a major problem in today's society $[1,2]$. STIs especially Chlamydia trachomatis and gonorrhea, are the most common infectious diseases reported by the US Department of Defense and the United States [3]. Overall transmission of STIs increases with people's involvement in high-risk sexual behaviors such as unprotected sex [4]. According to the latest official statistics of the Iranian Ministry of Health in the fourth quarter of 2015, 29,414 people infected with human immunodeficiency virus (HIV)/acquired immunodeficiency syndrome (AIDS) were registered in the country which $14.5 \%$ of them are sexually infected [5]. Approximately 7,000 people are added to the worldwide AIDS statistics [6].

Chlamydia and syphilis also cause approximately 350 million new infections worldwide each year, each increasing the risk of AIDS transmission. Chlamydia trachomatis causes $30-40 \%$ of cases of non-gonococcal urethritis. Syphilis is a chronic systemic infection almost all cases of which are transmitted sexually. The prevalence of chlamydia and syphilis in Iran is $18-29 \%$ and $0.2 \%$, respectively. In addition, human papillomavirus with an impact on carcinogenesis has been accepted in all types of human cancers, especially in the rectal region [7].

Modernization and Westernization have recently had significant impacts on society and culture among the major cities in Iran, and access to information about other cultures through technologies such as satellites and the Internet has played a crucial role in social change and tradition.

Adolescents in the United States are confronted with fundamental questions about sexual behaviors, including the consequences of STIs, pregnancy, sexual violence, and homosexual and bisexual behavior, which inappropriately are affected by these issues [8]. In investigating the knowledge, attitude and practice of students about STDs in Ethiopia more than half of students had heard of sexual and reproductive health, and knowledge of emergency contraception was limited [9]. Also in Malaysia the majority (86.6\%) of university student had heard of STDs, and 50.4\% knew STDs could present without symptoms. Chlamydia (26\%) and trichomonas (21.0\%) were rarely known. Among the sexually active students, $66.7 \%$ and $18 \%$ had sexual intercourse with multiple partners and commercial sex workers [10]. Information from East Africa about knowledge of STDs amongst university students remains sketchy. In Cameroon $70 \%$ of the university students knew about STDs but only $16.1 \%$ could name the clinical features of common STDs. Generally sexual practice patterns among university students lags behind knowledge and attitude towards prevention of STDs and condom use [11]. In Iran about 30\% of the population are 10-24 years old and most sexual negligence (55.6\%) occurs between the ages of 16 and 21 years [12]. In a study on Iranian young single males, more than onefourth had a history of sexual contact. In another study conducted in Mashhad, showed a 15\% prevalence of premarital sex in any time of university student life; $33 \%$ in males and $8 \%$ in females. On the other hand, a study by Farahani et al. showed a greater prevalence of some type of sexual relationship as $23 \%$ in female undergraduate students from universities of Tehran. In Iran, the actual prevalence of STIs is much higher than official data and the few recorded studies associated with sexual reproductive health of Iranian youth have indicated that the level of knowledge of reproductive health is low [13]. Iranian government policymakers are skeptical about providing reproductive and sexual health services to adolescents because the concept of adolescent reproductive and sexual health in Iran is new and controversial [14].

Worldwide, it is widely recognized that young people (people under the age of 25) are at greater risk of developing STIs. Studies have focused on the role of advice and education from reliable sources to prevent high-risk STIs in students [15] and also most knowledge, attitude and practices (KAP) studies in university students focused on HIV/AIDS while other STIs have been neglected [16-18]. Since prevention of four STIS - AIDS, chlamydia, syphilis and human papillomavirus - is one of the national programs, and cognition of knowledge, attitude and practice and other related variables in society can help to better plan for control of these disease, this study was designed to investigate the relationship between demographic variables and knowledge, attitude and practice of Islamic Azad University students about these four diseases in Tehran.

\section{Material and methods}

This study is a descriptive cross-sectional study conducted on 500 male and female students of Islamic Azad University of Tehran in May 2018. Azad University of Tehran has dif- 
ferent branches such as North, South, East, West and Center and each unit has got different faculties. Sampling was done by cluster random sampling through the selection of faculties in 5 units - North, South, East, West and Center of Tehran - and students were selected by convenience sampling. The data gathering tool was a researcher-made questionnaire that was prepared and adjusted using similar studies and under the supervision of professors in this field. Its validity was confirmed by content and face validity: Content validity was determined by sending a questionnaire to 9 health educators and an epidemiologist and determining the content validity index $(\mathrm{CVI}=0.93)$, which for knowledge, attitude and practice was $0.92,0.90,0.98$ respectively, and the content validity ratio $(C V R=0.97)$, which for knowledge, attitude, and practice was $0.98,0.93$, and 0.98 , respectively, using the Lawshe table. To determine the qualitative face validity, 15 targeted students were asked to read the questionnaire aloud and tell the observer whether there was any ambiguity. Quantitative face validity was obtained by calculating the impact score. We asked participants to rate each question on a scale of 1 to 5 . If one question gets an impact score of less than 1.5, it must be deleted, but the average impact score of our questions was 3.86 , so no questions were deleted. Reliability was assessed using the test-re-test method $(r=0.90)$.

Questions consisted of two parts: demographic characteristics including 5 questions and 34 questions about STIs which were divided into 11 questions of knowledge, 12 attitude and 11 practice. For sexually transmitted diseases (AIDS, syphilis, chlamydia, human papillomavirus), the questionnaire was completed by a self-administered questionnaire; 2 standard deviations below and above of the mean scores in knowledge, attitude and practice were considered low and high in knowledge, attitude and practice.

Sample size was calculated using Minitab software. Confidence interval $=95 \%, p=0.43, d=0.043, \alpha=0.5$. A total of 563 individuals were calculated. Finally, 500 questionnaires were completed and 63 questionnaires had not been completed properly and completely and therefore were excluded.

This study is the result of a research project with Code 1327 and Code of Ethics IR.SEMUMS.REC.1396.187 in Semnan University of Medical Sciences Student Research Committee. Data were analyzed using SPSS version 21 software and descriptive and inferential statistical tests such as $t$ test and ANOVA.

\section{Results}

In this study, 500 students in associate degree, bachelor level, and different fields such as engineering, art, etc. from 5 different units of Islamic Azad University of Tehran participated. $70.5 \%$ of students were between the ages of 18 and 22 years. The student selection in each unit was as equal as possible. Table 1 shows the student demographic variables.

Based on the findings of this study, the mean score of students' knowledge about STDs is $3.04 \pm 1.66$, which is well below the achievable score of 12 . Also, their attitude, preventive behaviors and risk behaviors mean scores were $37.7 \pm 5.54,2.93 \pm 0.89,2.42 \pm 1.84$ respectively.

In the present study, there was no significant relationship between students' mean score of knowledge and gender $(p=0.434)$, but a significant relationship was observed for attitude and practice (risk and preventive) with gender $(p<0.001)$ and for knowledge and attitude $(p<0.001)$ with marital status, with female gender being associated with a better attitude and practice and married women having better knowledge and attitude (Table 2).

Table 3 shows the frequency and percentage of sexually transmitted infections in the study population. More than half of students, both married and single, had a history of relationship with the opposite sex. More than 15\% of students in the past three months had sex outside the marriage. Nearly $30 \%$ of those surveyed had sex, of whom $11.5 \%$ had more than one partner. On the other hand, about $50 \%$ of them did not use a condom and more than $40 \%$ had a negative attitude towards condom use. Also they believed that using condoms would reduce their sexual proximity. And less than 35\% of them had taken action to raise awareness of STDs (AIDS, syphilis, etc.) on STDs.

Table 1. Students' demographic variables

\begin{tabular}{|c|c|c|}
\hline Demographic variables & Frequency & Percentage \\
\hline \multicolumn{3}{|l|}{ Azad University units } \\
\hline North & 103 & 20.3 \\
\hline East & 97 & 19.1 \\
\hline West & 100 & 19.7 \\
\hline South & 100 & 19.7 \\
\hline Center & 100 & 19.7 \\
\hline \multicolumn{3}{|l|}{ Sex } \\
\hline Female & 341 & 67.1 \\
\hline Male & 156 & 30.7 \\
\hline \multicolumn{3}{|l|}{ Marital status } \\
\hline Single & 438 & 86.2 \\
\hline Married & 56 & 11.0 \\
\hline \multicolumn{3}{|l|}{ Disciplines } \\
\hline Medicine & 2 & 0.4 \\
\hline Base sciences & 38 & 7.5 \\
\hline Engineering & 126 & 24.8 \\
\hline Art & 77 & 15.2 \\
\hline Human & 220 & 43.3 \\
\hline Others & 16 & 3.1 \\
\hline \multicolumn{3}{|l|}{ Age } \\
\hline $18-20$ & 196 & 38.6 \\
\hline $20-22$ & 162 & 31.9 \\
\hline 22 above & 103 & 20.5 \\
\hline Total & 500 & 100 \\
\hline
\end{tabular}


Table 2. Relationship between students' knowledge, attitude, gender, and marital status

\begin{tabular}{|c|c|c|c|c|c|c|c|c|}
\hline \multirow[t]{2}{*}{ Variables } & \multicolumn{2}{|c|}{ Risky behaviors } & \multicolumn{2}{|c|}{ Preventive behaviors } & \multicolumn{2}{|c|}{ Attitude } & \multicolumn{2}{|c|}{ Knowledge } \\
\hline & Mean & SD & Mean & SD & Mean & SD & Mean & SD \\
\hline Female & 2.11 & 1.68 & 3.000 & 0.84 & 38.86 & 5.08 & 3.01 & 1.61 \\
\hline Male & 3.08 & 2.004 & 2.78 & 0.99 & 35.83 & 5.33 & 3.15 & 1.76 \\
\hline$p$-value & \multicolumn{2}{|c|}{0.000} & \multicolumn{2}{|c|}{0.000} & \multicolumn{2}{|c|}{0.000} & \multicolumn{2}{|c|}{0.434} \\
\hline Single & 2.47 & 1.89 & 2.90 & 0.905 & 5.29 & 37.61 & 1.59 & 2.95 \\
\hline Married & 2.12 & 1.41 & 3.12 & 0.81 & 5.21 & 40.37 & 1.85 & 3.92 \\
\hline$p$-value & \multicolumn{2}{|c|}{0.102} & \multicolumn{2}{|c|}{0.086} & \multicolumn{2}{|c|}{0.000} & \multicolumn{2}{|c|}{0.000} \\
\hline Total mean & \multicolumn{2}{|c|}{2.42} & \multicolumn{2}{|c|}{2.93} & \multicolumn{2}{|c|}{37.79} & \multicolumn{2}{|c|}{3.04} \\
\hline SD & \multicolumn{2}{|c|}{1.84} & \multicolumn{2}{|c|}{0.89} & \multicolumn{2}{|c|}{5.54} & \multicolumn{2}{|c|}{1.66} \\
\hline Max & \multicolumn{2}{|c|}{6} & \multicolumn{2}{|c|}{4} & \multicolumn{2}{|c|}{50} & \multicolumn{2}{|c|}{9} \\
\hline Min & \multicolumn{2}{|c|}{0} & \multicolumn{2}{|c|}{0} & \multicolumn{2}{|c|}{18} & \multicolumn{2}{|c|}{0} \\
\hline Highest achievable score & \multicolumn{2}{|c|}{6} & \multicolumn{2}{|c|}{4} & \multicolumn{2}{|c|}{60} & \multicolumn{2}{|c|}{12} \\
\hline Lowest achievable score & \multicolumn{2}{|c|}{0} & \multicolumn{2}{|c|}{0} & \multicolumn{2}{|c|}{12} & \multicolumn{2}{|c|}{0} \\
\hline
\end{tabular}

Table 3. Frequency and percentage of sexually transmitted infections in the study population

\begin{tabular}{|c|c|c|}
\hline Behaviors questions & Frequency & Percentage \\
\hline \multicolumn{3}{|c|}{ Have you ever had a relationship with the opposite sex? } \\
\hline Yes & 271 & 55.5 \\
\hline No & 216 & 44.5 \\
\hline
\end{tabular}

Have you had sex outside of marriage during the past three months?

\begin{tabular}{l|c|c}
\hline Yes & 75 & 15.2 \\
\hline No & 420 & 84.8 \\
\hline
\end{tabular}

How many people have you had sex with?

\begin{tabular}{l|c|c}
\hline 1 & 74 & 15 \\
\hline 2 & 24 & 4.9 \\
\hline 2 & 49 & 6.6 \\
\hline I didn't have sex & 347 & 70.2 \\
\hline
\end{tabular}

I believe that using condoms during sex reduces sexual pleasure.

\begin{tabular}{l|c|c}
\hline strongly agree & 197 & 41.7 \\
\hline No idea & 227 & 46.9 \\
\hline strongly disagree & 60 & 12.4 \\
\hline
\end{tabular}

Have you used condoms in this relationship if you have sex outside of marriage?

\begin{tabular}{l|l|l}
\hline Yes & 74 & 50.3 \\
\hline No & 73 & 49.6 \\
\hline
\end{tabular}

If you have sex outside of marriage have you ever checked your partner for sexually transmitted diseases (AIDS, syphilis, etc.) before having sex?

\begin{tabular}{l|c|c}
\hline Yes & 40 & 27.2 \\
\hline No & 107 & 72.8 \\
\hline
\end{tabular}

Have you ever taken action to raise awareness of STDs (AIDS, syphilis, etc.)?

\begin{tabular}{l|l|l}
\hline Yes & 167 & 34.2 \\
\hline No & 323 & 65.8 \\
\hline
\end{tabular}

The ANOVA and Kruskal-Wallis test and the LSD test showed no significant difference between their field of students of Azad University with their knowledge. But in Tehran center students' attitude was better than other students' $(\mathrm{C}>\mathrm{W}, \mathrm{E}, \mathrm{N}, \mathrm{S})$ and in students' preventive behaviors there was no significant difference between units. But in Tehran center was significantly less risk behavior than Tehran East. On the other hand, there was no statistically significant difference in attitude and knowledge among students of different disciplines, except that they had a better attitude in the field of human science than art $(\mathrm{H}>\mathrm{A})$. In terms of preventive practice students in basic science were the best and students in medicine were the worst. Students in basic science and art were better than the others. Risk behaviors in medical students were the highest and in the students in basic science were the least (Table 4).

According to Table 5, knowledge, risky and preventive behaviors had significant correlations with age, so that as people's age increase, their knowledge and preventive behavior $(r=0.101)$ and risky behavior $(r=0.160)$ also weakly increase. Knowledge had correlations with risky $(0.134)$ and preventive behaviors (0.119). Attitude (-0.274) and preventive behaviors $(-0.273)$ had negative correlations with risky behaviors.

Students reported the Internet as the way of acquiring knowledge about STDs with the highest percentage (28.8\%) followed by social media (23.2\%) and the lowest rate was for radio followed by health care providers and professors (Table 6).

\section{Discussion}

The present study aimed to determine the relationship between demographic variables and the knowledge, attitude and practice of students of Islamic Azad University. The knowledge of most students about STIs (AIDS, chla- 
mydia, syphilis and human papillomavirus) was very low. According to the results the performance of the study population in the field of STIs is worrying, because more than half of people had a history of having relationship with the opposite sex regardless of underreporting $(15.2 \%$ reported sex outside marriage but $26.4 \%$ reported having sex with one or more partner). The message of abstinence emphasizes avoiding extreme danger (not having sex outside of marriage). Although this theory is desirable in today's cultural, religious, and social contexts, it is no longer realistic, and many people in practice do not abstain from sexual behavior; the efficacy of approaches to reduce the risk of transmission and to prevent these diseases has been proven in high-income countries. A systematic review study showed that messaging coverage on reducing sexual risk had a positive effect compared to messages that only spoke of refusing to have sex [19].

In a study of sexually transmitted diseases in Ethiopia, discussions between parents and adolescents about sex were poor. Attempts are needed to empower teens and communities about proper sexual health and reproduction. The study suggested that university curricula should be reviewed and health facilities must be provided for sex education [20]. Studies have found that in the face of millions of new infections and significant financial costs of medication, sexual behavior change interventions are crucial in the fight against HIV/AIDS. In spite of that, there is little evidence of sexual health education, and the dominant approach to preventing these diseases in young people is to avoid sex [4].

On the other hand, in this study, the attitude and practice score was estimated as average, which indicates the existence of misconceptions among students, given the large amount of damage that STIs cause for the community and as HIV is untreatable. It is becoming more and more apparent that the authorities need to pay attention to this issue. The percentage of these results indicates that the majority of the population did not believe in the adequacy of efforts made in terms of the preventive behaviors. However, because of the taboo of these arguments in the society it can lead to social bigotry and lack of reporting. Oral and anal sex is increasingly reported among adolescents and young people in high-income countries. In addition, intraoral and anal STIs may lead to adverse health outcomes such as oral and anal cancer [21].

High-risky behaviors in the study community were worrying. Having relationships with the opposite sex, having sex with multiple partners, a negative attitude towards condom use during sexual intercourse and not using one during sexual intercourse was worrying.

According to the results of this study and other studies, students at the university are placed in an environment that contributes to sexual risk factors, including having sex with casual partners, having 3 or more partners, and no regular use of preventive devices such as condoms during intercourse. Typically, older students (18-24 years old) are part of the age group with the highest new human burden of detecting HIV/AIDS in the United States. In a study of American students, half of the participants were sexually active




Table 5. Relationship of performance, attitude and awareness with age

\begin{tabular}{c|c|c|c|c|c}
\hline & Age & Knowledge & Attitude & Risky behaviors & Preventive behaviors \\
\hline Age & 1 & & & & \\
\hline Knowledge & $0.258^{\star}$ & 1 & & & \\
\hline Attitude & 0.023 & 0.056 & 1 & & \\
\hline Risky behaviors & $0.160^{\star *}$ & $0.134^{\star *}$ & $-0.274^{\star *}$ & 1 & \\
\hline Preventive behaviors & $0.101^{\star *}$ & $0.119^{\star *}$ & $0.137^{\star *}$ & $-0.273^{\star}$ & 1 \\
\hline
\end{tabular}

Table 6. Absolute and relative frequency of STDs, STD signs and source of knowledge about STDs

\begin{tabular}{l|c|c}
\hline & Frequency & Percentage \\
\hline Have you ever had STDs? \\
\hline Yes & 2 & 4 \\
\hline No & 486 & 99.6 \\
\hline
\end{tabular}

\begin{tabular}{l|c|c}
\hline \multicolumn{3}{l}{ If yes, which kind of STDs have you experienced? } \\
\hline Syphilis & 0 & 0 \\
\hline HIV & 0 & 0 \\
\hline Chlamydia & 1 & 0.2 \\
\hline Genital warts & 0 & 0 \\
\hline Other cases & 1 & 0.2 \\
\hline
\end{tabular}

If yes, what were the STD signs?

\begin{tabular}{l|c|c}
\hline Wounds and warts & 0 & 0 \\
\hline Inflation and redness & 1 & 0.2 \\
\hline Funky discharge & 0 & 0 \\
\hline Itching & 4 & 0.8 \\
\hline Dysuria & 0 & 0
\end{tabular}

What was the source of acquiring information?

\begin{tabular}{l|c|c}
\hline TV & 34 & 6.8 \\
\hline Radio & 12 & 2.4 \\
\hline Health centers & 24 & 4.8 \\
\hline Physician & 35 & 7 \\
\hline Social networks & 116 & 23.2 \\
\hline Friends & 55 & 11 \\
\hline Family and relatives & 34 & 6.8 \\
\hline Professors & 28 & 5.6 \\
\hline Internet & 144 & 28.8 \\
\hline Book & 51 & 10.2 \\
\hline Total & 500 & \\
\hline
\end{tabular}

and they had never undergone HIV testing. Respondents had different levels of SRF [22].

In this study, females had better attitude and preventive behaviors and less risky behaviors. Married women had better knowledge and attitude. In a study by Gary et al., men reported more than women never having needed sex counseling or treatment for sexually transmitted diseases [15]. Male students' lack of involvement with these services can be of concern. Motivation of young people to marriage and commitment and also reduction of the barriers to marriage and improving student performance through education and especially commitment which may reduce the risk of engaging in high-risk sexual behaviors are recommended.

In general, different departments of Azad University and various disciplines, especially non-medical disciplines, require deeper training in sexuality and sexually transmitted diseases. In this study because just two medical students participated it cannot be generalized. Four of the interventions were developed using three-structure information, motivation and behavioral skill models, and all four interventions significantly increased condom use or condom use intentions. Interventions that included models of increasing self-efficacy for condom use, teaching participants how to obtain a condom and how to negotiate condom use with their partners, were more likely to use condoms or intend to use condoms [23]. One study showed that free STI testing can be effective in student participation in testing [24].

Students reported the highest percentage of acquiring information about STIs on the Internet, followed by social media, and the lowest rate of acquiring information about STIs on the radio, followed by health centers and professors. Worldwide, it is widely recognized that young people (people under the age of 25) are at greater risk of developing STIs. In order to prevent these STIs in this age group, it is important to get reliable advice and education. In a Malaysian study knowledge of STDs via the Internet, social networks, and health staff was positively related to having better knowledge about STDs in university students [10]. Consistent with our study, in a study it was reported that the students mainly obtained STD information through the Internet, newspapers, or magazines [25].

Among the limitations of this study are the self-report method and failure to perform an STI diagnosis test to measure performance. In future studies, it is recommended that a variety of intervention methods be designed and implemented to evaluate the best way to influence students' knowledge, attitude and practice.

\section{Conclusions}

According to the study, the knowledge of Azad University students about the four diseases of AIDS, chlamydia, syphilis and human papilloma is very low. The attitude toward these diseases and practice was moderate. Because 
of the relationship of knowledge and attitude with marital status, it is recommended to promote timely marriage and family formation and to provide marriage facilities to students to prevent and control these diseases. On the other hand, based on the results of this study, further information and inclusion of more solid sex education in the academic curriculum and also the establishment of valid websites, blogs and channels by medical universities, mass community campaigns through the Internet and social medias, and the use of online health care providers in order to improve awareness of STDs, with the focus on male students and single students, who need more education and attention, are recommended. Although this study has some strengths such as a high sample size, it had some limitations such as gathering information by self-administered questionnaire, which increase the rate of bias. The next studies must focus on designing educational content for students and lobbying and negotiation to integrate it into the curriculum.

\section{Acknowledgments}

The authors of this article would like to express their gratitude to the officials of Semnan University of Medical Sciences, the officials of Islamic Azad University in different units of Tehran, especially security officials, students and professors of Islamic Azad University, and all the dear ones who helped us in this project.

\section{Conflict of interest}

The authors have no conflict of interest.

\section{References}

1. Peckham S, Hann A, Kendall S, Gillam S. Health promotion and disease prevention in general practice and primary care: a scoping study. Prim Health Care Res Develop 2017; 18: 529-540.

2. Astle S, McAllister P, Emanuels S, Rogers J, Toews M, Yazedjian A. College students' suggestions for improving sex education in schools beyond 'blah blah blah condoms and STDs'. Sex Education 2021; 21: 91-105.

3. Harbertson J, De Vera K, Scott PT, et al. Longitudinal survey of condom use across a US Navy and Marine Corps shipboard deployment. BMJ Open 2019; 9: e028151.

4. Teimori F, Kariman N, Mansori F, et al. Prevalence of risky behaviours and STD in women reffered to addiction kermanshah nilofar center (2009, 2010). Kermanshah University J 2011; 15: 400.

5. Mahdizadeh J. Human papilloma virus and Tp53 gene mutation in oral tongue SCC and their correlation with tumor characteristics: a multi-center study. Iranian Journal of Otorhinolaryngology 2010; 22: 16-17.

6. Yazdi-Ravandi STZ, Ghaleiha A, Azhdarloo M, Shamsaei F. Knowledge and attitude in Hamadan University of Medical Sciences students toward AIDS: a cross-sectional study from West of Iran. Scientific Researchers 2017; 4: 103-106.

7. Rahmati Najarkolaie F, Khobdel M, Ghasemi M, Farmanbar R, Jafari MR, Khah TK. Knowledge and high risk behaviors of newly entered students to Tehran University toward HIV/AIDS. J Holist Nurs Midwifery 2013; 23: 35-44.

8. Hall WJ, Jones BLH, Witkemper KD, Collins TL, Rodgers GK. State policy on school-based sex education: a content analysis focused on sexual behaviors, relationships, and identities. Am J Health Behav 2019; 43: 506-519.

9. Tamire W, Enqueselassie F. Knowledge, attitude, and practice on emergency contraceptives among female university students in Addis Ababa, Ethiopia. Ethiopian Journal of Health Development 2007; 21: 111-116.

10. Folasayo AT, Oluwasegun AJ, Samsudin S, Saudi SN, Osman M, Hamat RA. Assessing the knowledge level, attitudes, risky behaviors and preventive practices on sexually transmitted diseases among university students as future healthcare providers in the Central Zone of Malaysia: a cross-sectional study. Int J Environ Res Public Health 2017; 14: 159.

11. Sekirime WK, Tamale J, Lule JC, Wabwire-Mangen F. Knowledge, attitude and practice about sexually transmitted diseases among university students in Kampala. Afr Health Sci 2001; 1: 16-22.

12. Najmabadi M, Babazadeh R, Mousavi SA, Shariati M. Iranian adolescent girls' challenges in accessing sexual and reproductive health information and services. J Health 2018; 8: 561-574.

13. Hedayati-Moghaddam MR, Eftekharzadeh-Mashhadi I, Fathimoghadam F, Pourafzali SJ. Sexual and reproductive behaviors among undergraduate university students in Mashhad, a city in Northeast of Iran. J Reprod Infertil 2015; 16: 43-48.

14. Nagmabadi KM, Babazadeh R, Shariati M, Mousavi SA. Iranian adolescent girls and sexual and reproductive health information and services: a qualitative study. Iranian Journal of Obstetrics, Gynecology and Infertility 2014; 17: 9-18.

15. Gray BJ, Jones AT, Couzens Z, Sagar T, Jones D. University students' behaviours towards accessing sexual health information and treatment. Int J STD AIDS 2019; 30: 671-679.

16. Pourjam R, Rahimi Khalifeh Kandi Z, Estebsari F, et al. An analytical comparison of knowledge, attitudes, and practices regarding HIV/AIDS among medical and non-medical students in Iran. HIV AIDS (Auckl) 2020; 12: 165-173.

17. Shokoohi M, Karamouzian M, Mirzazadeh A, et al. HIV knowledge, attitudes, and practices of young people in Iran: findings of a national population-based survey in 2013. PLoS One 2016; 11 : e0161849.

18. Esmaeilzadeh S, Allahverdipour H, Fathi B, Shirzadi S. Risk perception of HIV/AIDS and low self-control trait: explaining preventative behaviors among Iranian university students. Glob J Health Sci 2015; 8: 44-52.

19. Angrist N, Matshaba M, Gabaitiri L, Anabwani G. Revealing a safer sex option to reduce HIV risk: a cluster-randomized trial in Botswana. BMC Public Health 2019; 19: 610.

20. Furry DB, Mashalla Y, Tshweneagae GT. Sexual and reproductive health among high school adolescents in west Shoa zone, Oromia region in Ethiopia. Afr J Reprod Health 2019; 23: 65-72.

21. Morhason-Bello IO, Kabakama S, Baisley K, Francis SC, WatsonJones D. Reported oral and anal sex among adolescents and adults reporting heterosexual sex in sub-Saharan Africa: a systematic review. Reprod Health 2019; 16: 48.

22. James TG, Cheong J, Ryan SJ. Sexual risk factors and human immunodeficiency virus testing intention among at-risk college students who have never been tested. Sex Trans Dis 2019; 46: e76-e79.

23. Whiting W, Pharr JR, Buttner MP, Lough NL. Behavioral interventions to increase condom use among college students in the United States: a systematic review. Health Educ Behav 2019; 46: 877-888.

24. Keizur EM, Bristow CC, Baik Y, Klausner JD. Knowledge and testing preferences for Chlamydia trachomatis, Neisseria gonorrhoeae, and Trichomonas vaginalis infections among female undergraduate students. J Am Coll Health 2020; 68: 754-761.

25. Anwar M, Sulaiman SA, Ahmadi K, Khan TM. Awareness of school students on sexually transmitted infections (STIs) and their sexual behavior: a cross-sectional study conducted in Pulau Pinang, Malaysia. BMC Public Health 2010; 10: 47. 